\title{
A New Optimized Rotor Design for Brushless Doubly Fed Machines
}

\author{
Salman Abdi ${ }^{1}$, Ashknaz Oraee ${ }^{2}$, Ehsan Abdi $^{2}$, and Richard McMahon ${ }^{1}$ \\ ${ }^{1}$ Warwick Manufacturing Group (WMG), University of Warwick, Coventry, UK \\ ${ }^{2}$ Wind Technologies Limited, St John's Innovation Centre, Cambridge, UK \\ Email: s.abdi.jalebi@gmail.com
}

\begin{abstract}
The brushless doubly fed machine (BDFM) is an alternative to the doubly fed induction generator, widely used in wind turbines, without use of brush gears and slip rings. Rotor design is important for designing an optimal multi-MW BDFM. To date, nested-loop rotors have been extensively used in various BDFMs but they may not be suitable for larger machines. In this paper, different methods of BDFM rotor equivalent circuit parameters determination are presented and validated by experimental tests. Then, a design optimization of BDFM rotors is proposed based on equivalent circuit analysis with the aim of minimizing the rotor parameters. Two optimized rotors, one bar cage rotor and one nested-loop rotor were designed and built from the outcomes of the optimization method for a BDFM with frame size D180. The characteristics of the conventional and optimized rotors in terms of the rotor equivalent circuit parameters and iron saturation at rated operating conditions are compared using analytical and Finite Element Analysis (FEA) methods.
\end{abstract}

Index Terms-Brushless Doubly Fed Machine (BDFM), Finite Element Analysis (FEA), Nested loop rotor, Equivalent circuit analysis.

\section{INTRODUCTION}

The BDFM shows commercial promise as both a variable speed drive and generator. As a generator, it is particularly attractive for wind power generation as a replacement for doubly-fed slip-ring generators, since it offers a key advantage of variable speed operation with greater reliability while requiring only a fractionally rated converter [1]. To date, there have been several attempts to manufacture large BDFMs, for example in Brazil with a $75 \mathrm{~kW}$ machine [2], China with a $200 \mathrm{~kW}$ machine [3], and the $250 \mathrm{~kW}$ BDFM reported by the authors in [4], as stepping-stones towards a megawatt scale BDFM wind turbine. To achieve successful large MW-scale BDFMs with desirable performance, it is essential to optimize the BDFM design, including its rotor characteristics.

The BDFM has two windings on a common stator core, one connected directly to the grid, called the power winding (PW), and the other supplied from a variable voltage and frequency converter, called the control winding $(\mathrm{CW})$. The stator windings are configured for different, non-coupling pole numbers $\left(p_{1}\right.$ and $p_{2}$ associated with stator PW and stator $\mathrm{CW}$, respectively). A schematic of the BDFM grid connections is shown in Fig. 1. A special rotor is required to couple with the two stator windings. The machine is normally run in a synchronous mode, with an appropriate controller, in which the rotor speed is determined by the stator supplied frequencies. In this mode, the BDFM operates in a similar way to the doubly fed induction generator with torque that can be varied by adjusting the control winding voltage.

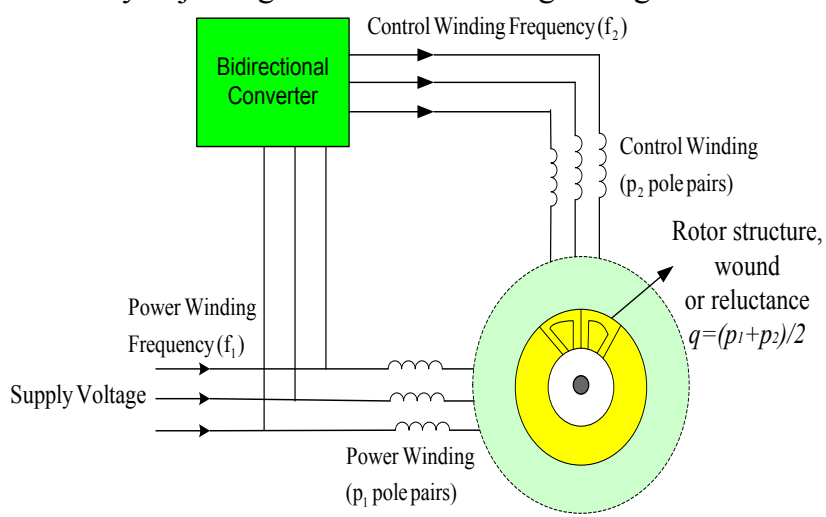

Fig. 1. Schematic of BDFM grid connection.

Broadway et al. proposed a number of BDFM rotor designs in [5], among them a $p_{1}+p_{2}$ bar cage rotor was proposed as a simple way of producing principal fields. The nested-loop rotor was reported in [6] as a development of the $p_{1}+p_{2}$ bar cage rotor design comprising $p_{1}+p_{2}$ nests each with multiple concentric loops. Nested-loop type rotors have been widely used in recent BDFMs due to their higher torque production and relatively simple structure [4]. In [7] where a comparison between cage and nested-loop rotors was carried out and various prototype rotors assessed experimentally. A rotor design was proposed in [8] with equal current in all loops of a nest resulting in a reduced rotor leakage inductance but increased rotor resistance. McMahon et al. [9] characterized BDFM rotors using an analytical parameter calculation method using winding factors, where the magnetizing inductances associated with harmonic fields were neglected. Rotor parameters were compared for both nested-loop and series wound rotors.

In this paper, various analytical and numerical methods for rotor equivalent circuit parameters calculation are assessed and their practicalities are verified by performing experimental tests on three prototype BDFMs. Then, a design optimization method is proposed based on equivalent circuit analysis with an aim of minimizing the rotor equivalent circuit parameters. The optimization method is then used to design and build a nested-loop rotor and a bar-cage rotor for a D180 frame BDFM. The characteristics of the optimized rotors in 
terms of the rotor equivalent circuit parameters and iron saturation at rated operating conditions are assessed and compared with existing rotors using analytical and Finite Element Analysis (FEA).

TABLE I

PROTOTYPE BDFMS SPECIFICATIONS

\begin{tabular}{lccc}
\hline Frame size & D160 & D180 & D400 \\
\hline PW pole Number & 4 & 4 & 4 \\
CW pole Number & 8 & 8 & 8 \\
$\begin{array}{l}\text { Speed range } \\
\text { Rated torque }\end{array}$ & $700 \mathrm{rpm} \pm 32 \%$ & $750 \mathrm{rpm} \pm 33 \%$ & $500 \mathrm{rpm} \pm 36 \%$ \\
Rated power & $5 \mathrm{~kW}$ at 700 & $7.8 \mathrm{~kW}$ at 750 & $250 \mathrm{~kW}$ at 680 \\
Efficiency & rpm & rpm & rpm \\
Stack length & $>91 \%$ & $>93 \%$ & $>95 \%$ \\
$\begin{array}{l}\text { Stator slots } \\
\text { Rotor slots } \\
\text { (nested loop) }\end{array}$ & $0.19 \mathrm{~m}$ & $0.19 \mathrm{~m}$ & $0.82 \mathrm{~m}$ \\
$\begin{array}{l}\text { Rotor slots } \\
\text { (bar cage) }\end{array}$ & 36 & 48 & 72 \\
\hline
\end{tabular}

\section{EXPERIMENTAL BDFMS}

The specifications of the prototype BDFMs used in this study are shown in Table I. These BDFMs have fourand eight-pole stator windings and were constructed in frame sizes of 400, 180 and 160 with the stack lengths of 820,190 and $190 \mathrm{~mm}$, respectively. The stator windings in all machines were connected in delta. The rotor configurations include the nested loop rotor comprising $p_{1}+p_{2}$ sets of nests each having concentric loops, see Fig. 2 , and the cage rotor with $p_{1}+p_{2}$ bars and an enclosing cage bars, see Fig. 3.

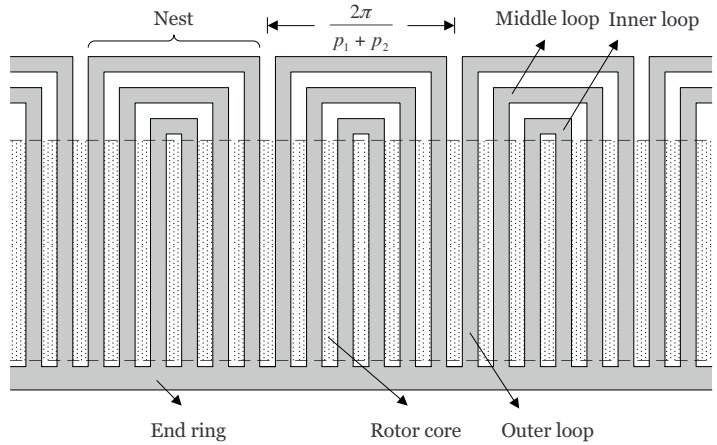

(a) Schematic of the nested-loop rotor

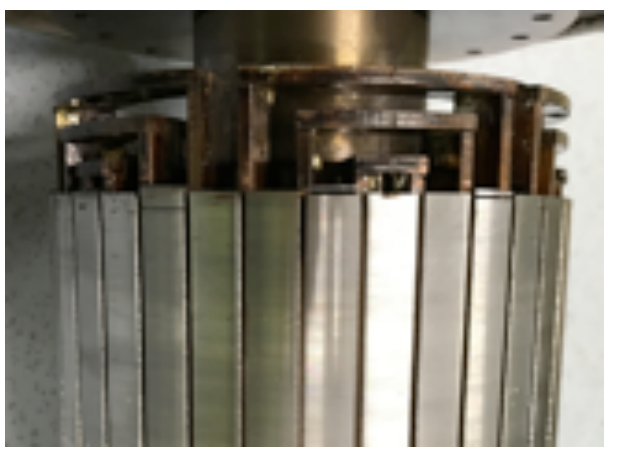

(b) Prototype nested-loop rotor

Fig.2: D180 BDFM nested-loop rotor configuration

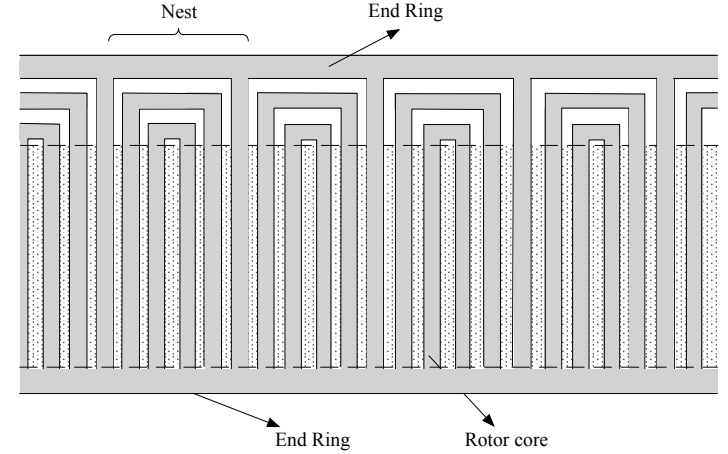

(a) Schematic of the bar cage rotor

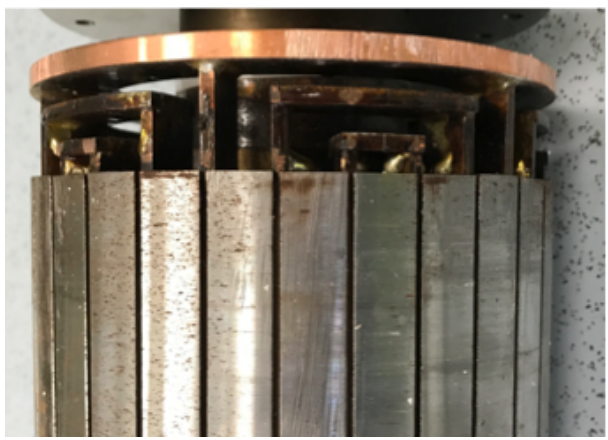

(b) Prototype bar cage rotor

Fig. 3: D180 BDFM bar cage rotor configuration

\section{BDFM EQUIVALENT CIRCUIT ANALYSIS}

The equivalent circuit is a simple method of representing the steady-state performance of the BDFM, allowing rapid calculation of its operating conditions. A simplified equivalent circuit for the BDFM is shown in Fig. 4, where all parameters are referred to the PW side and iron losses are neglected [10]. $R_{1}$ and $R_{2}$ are the stator resistances, $L_{m 1}$ and $L_{m 2}$ are the stator magnetizing inductances and $L_{1}$ and $L_{2}$ are the stator leakage inductances. The circuit is valid for all the modes of operation, including the induction, cascade, and synchronous modes and can be utilized for the analysis of steady-state performance of the BDFM [10]. $s_{1}$ and $s_{2}$ are the power and control winding slips and are defined as

$$
\begin{aligned}
& s_{1}=\frac{\omega_{1}-p_{1} \omega_{r}}{\omega_{1}} \\
& s_{2}=\frac{\omega_{2}-p_{2} \omega_{r}}{\omega_{2}}
\end{aligned}
$$

where $\omega_{1}$ and $\omega_{2}$ are the angular frequencies of the PW and $\mathrm{CW}$, and $\omega_{r}$ is the shaft angular speed.

Rotor parameters are important in determining the machine performance including pull out torque and lowvoltage ride through requirements in wind turbine applications [11]. The rotor can be characterized by the rotor turns ratio $n_{r}$, resistance $R_{r}$ and leakage inductance $L_{r}$, the two latter parameters are also shown in the referred per-phase equivalent circuit of Fig. 4. The rotor leakage inductance is formed from conventional leakage elements and harmonic inductance terms from the space harmonics generated by the rotor. The harmonic nature of the BDFM 


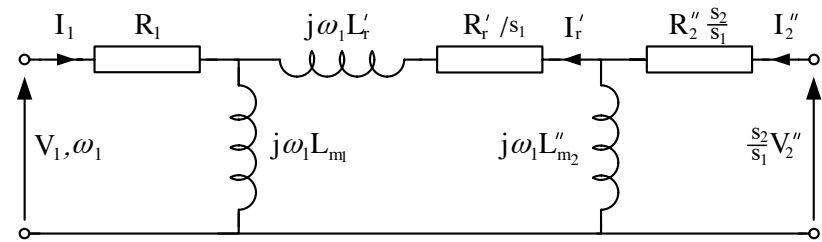

Fig. 4: Referred per phase equivalent circuit of the BDFM rotor results in a higher differential leakage component compared to other machines.

The rotor turns ratio is a measure of the relative magnitudes of the magnetic field components the rotor couples. It is shown in [12] that for given values of machine stack length, air gap diameter, and electric and magnetic loadings, the maximum output power can be obtained for an optimum rotor turns ratio of:

$$
n_{r_{o p t}}=\left(p_{1} / p_{2}\right)^{1 / 2}
$$

The BDFM rotor design objective is therefore to make a rotor with turns ratio close to its optimum value. It is also shown in [12] that the maximum machine rating is not sensitive to the rotor turns ratio. Hence, the value of turns ratio being close to its optimal value can be traded off against gaining other performance measures such as efficiency and low voltage ride-through (LVRT). Moreover, to obtain better machine performance such as higher efficiency and controllability, the rotor leakage inductance and resistance must be at a minimum.

Below, different methods of obtaining the BDFM equivalent circuit parameters including the rotor parameters are briefly discussed. The rotor parameters are then calculated for three experimental BDFMs, a frame size D160 machine [12], a frame size D180 machine [13], and a D400 $250 \mathrm{~kW}$ machine [14]. The results are compared with the rotor parameters obtained from experimental tests.

\section{A. Coupled Circuit Method (CCM)}

The equivalent circuit parameters can be calculated from the machine geometry, during the design stage, using the method described in [10]. The procedure involves deriving the machine's coupled-circuit model, followed by performing a series of transformations to obtain the $d q$ sequence components and equivalent circuit parameters, respectively.

\section{B. Winding Factor Method (WFM)}

The winding factor method and its experimental verification are described in [13]. This method of parameter determination centres on the loops of the nested loop or bar cage rotor, which are effectively in parallel and have mutual couplings via the principal fields and their space harmonics. Each loop has winding factors for the principal fields, magnetizing inductances for each space harmonic, emfs produced by mutual inductances for the various space harmonics in response to the flow of currents in other rotor loops and via coupling to the stator. In addition, each loop has a leakage reactance, which can be estimated by conventional means and a resistance, which can be calculated or measured. It should be noted that rotor parameters obtained from the winding factor method are speed dependent. However, it is shown in [13] that this dependency over the operating speed range is negligible.

\section{FEA/Experimental Method}

The equivalent circuit parameters can also be extracted from steady-state measures, such as torque, speed, voltages, and currents, obtained from BDFM's operation in the induction and cascade modes [14], as shown in the block diagram of Fig. 5. The steady-state data can be obtained from numerical models e.g. Finite Element Analysis (FEA) or experimental tests. The stator winding resistances, $R_{l}$ and $R_{2}$, are either calculated from the machine geometry at a certain operating temperature or obtained from DC measurements. The magnetizing inductances, $L_{m 1}$ and $L_{m 2}$, are obtained from the magnetizing tests where a single stator winding is supplied in turn while the other winding is left open and the rotor is driven at the synchronous speed to eliminate rotor currents. Finally, the rotor parameters $L_{r}{ }_{r}$ and $R_{r}{ }_{r}$ are obtained from applying a curve fitting method to the data from cascade tests, assuming the stator resistance and magnetizing parameters are fixed [14].

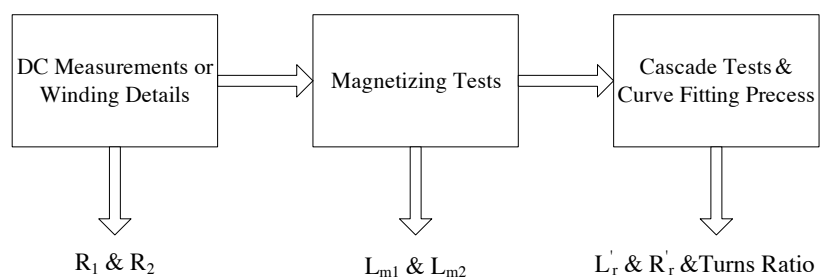

Fig. 5: Extraction of equivalent circuit parameters from numerical modeling or experimental measurements

\section{Rotor Parameters for Prototype BDFMs}

The rotor equivalent circuit parameters for the three BDFMs are determined using the methods described above, see Table II. Note that the close agreement between the parameters calculated from analytical/FEA methods and the parameters obtained from experimental tests for all prototype BDFMs shows the validity of proposed methods.

\section{BDFM Rotor DESIGN OPTIMIZATION}

\section{A. Rotor Loop Span and Number of Loops}

The aim of rotor optimization is to achieve a rotor with near to optimum turns ratio while keeping $L_{r}$ and $R_{r}$ within the desired range for maximum efficiency. The optimization process is also restricted by the machine design specifications such as requirements on pull-out torque, reactive power management and low voltage ridethrough capability. In the optimization problem, turns ratio and skin effect were taken as design constraints. In this paper, the influence of loop span and the number of loops on the rotor parameters for the nested-loop and the $p_{1}+p_{2}$ bar cage rotors is studied. 
TABLE II

COMPARISON OF ROTOR PARAMETERS OBTAINED FROM DIFFERENT EQUIVALENT CIRCUIT PARAMETERS DETERMINATION METHODS

\begin{tabular}{lccccc}
\hline BDFM & Parameter & CCM & WFM & FEA & Experiment \\
\hline \multirow{2}{*}{ D160 } & $R^{\prime}{ }_{r}(\Omega)$ & 3.51 & 3.31 & 3.42 & 3.54 \\
& $L^{\prime}{ }_{r}(m H)$ & 43.5 & 45.7 & 41.7 & 39.3 \\
& $n_{r}$ & 0.753 & 0.792 & 0.790 & 0.783 \\
\hline \multirow{2}{*}{ D180 } & $R^{\prime}{ }_{r}(\Omega)$ & 1.68 & 1.72 & 1.53 & 1.6 \\
& $L^{\prime}{ }_{r}(m H)$ & 56.5 & 56.7 & 56 & 54 \\
& $n_{r}$ & 0.703 & 0.716 & 0.678 & 0.720 \\
\multirow{2}{*}{ D400 } & $R^{\prime}{ }_{r}(\Omega)$ & 0.115 & 0.115 & 0.12 & 0.114 \\
& $L{ }^{\prime}{ }_{r}(m H)$ & 16 & 16.5 & 15.2 & 12.5 \\
& $n_{r}$ & 0.359 & 0.366 & 0.355 & 0.380 \\
\hline
\end{tabular}

The referred rotor inductance $L^{\prime}{ }_{r}$ in the simplified circuit shown in Fig. 4 represents the series inductances in the full equivalent circuit [10], including the stator PW and $\mathrm{CW}$ leakage inductances and conventional rotor leakage inductances.

The rotor resistance and conventional leakage components of the rotor inductance do not vary significantly with changes in the loop span. Nevertheless, magnetizing inductance is considerably influenced by the variation of loop spans as well as the ratio of $\mathrm{PW}$ and $\mathrm{CW}$ pole pairs, as can be seen from (4),

$$
L_{m}=\frac{\mu_{0}}{g} \frac{l d q}{\pi}\left(\frac{N_{e f f}}{p}\right)^{2}
$$

obtained for $p$ pole-pair space harmonics. $N_{\text {eff }}$ is the effective turns corresponds to each pole and $g$ is the air gap length. According to (4), the magnetizing inductance in a machine with uniform air gap is inversely proportional to the square of the harmonic pole pairs of the magnetized field. The MMF, magnetizing each field is determined by the harmonic winding factor of the winding. The winding factor, $k_{w}$, for a single rotor loop is given by:

$$
k_{w}=\sin \left(\beta \frac{p}{2}\right) \frac{\sin \left(w_{s r} p / 2\right)}{w_{s r} p / 2}
$$

where $\beta$ is the coil span of the loop, $p$ is the harmonic pole pair and $w_{s r}$ is the slot mouth in radians. It should be noted that to achieve a nested-loop rotor with six nests and a maximum of three loops per nest, and a bar cage rotor design with six bars and a maximum of three internal loops, the minimum number of rotor slots must be 36 and 42 respectively. These numbers of rotor slots are hence considered in the following analysis.

To achieve minimum rotor $L_{r}^{\prime}$ and $R_{r}^{\prime}$ in a nested-loop design, loops are added progressively to the nests and loop spans are adjusted for equal slot spacing. The optimization procedure is then similarly performed on the $p_{1}+p_{2}$ bar cage rotor with arbitrary pitch and placement. This can be achieved by adding concentric loops progressively adjusting all the loop spans by increments of one degree. The $R^{\prime}{ }_{r}$ and $L^{\prime}{ }_{r}$ obtained for the 36-slot nested-loop rotor of D180 BDFM with different number of loops are shown in Table III using coupled circuit and winding factor methods.

It can be seen from Table III that adding loops to the rotor nests corresponds to a lower harmonic leakage inductance due to the addition of steps in the mmf pattern. Furthermore, loops with larger spans have a much lower referred rotor leakage inductance and resistance, hence give better results on the chosen measure of the machine performance.

A similar procedure was applied to a 42-slot bar cage rotor of the D180 $\mathrm{BDFM}$ with $p_{1}+p_{2}$ bars in order to further optimize rotor parameters. The number of slots is chosen in a way that a maximum of three internal loops between the two bars of the bar cage structure is achievable and therefore a comparison of rotor parameters obtained from these two rotor designs with the same number of loops can be performed. Table IV shows the effect of adding loops to the $p_{1}+p_{2}$ bar cage resulting in a reduced referred rotor leakage inductance and resistance.

The $L_{r}{ }_{r}$ and $R_{r}{ }_{r}$ obtained for the two rotors for the three-loop case are shown in the last columns of Table III and IV. It is evident that both $L_{r}{ }_{r}$ and $R_{r}{ }_{r}$ are significantly lower in a bar cage rotor than a nested-loop rotor for a given BDFM.

TABLE III

PARAMETER CALCULATION OF 36-SLOT NESTED-LOOP ROTOR WITH DIFFERENT NUMBER OF LOOPS FOR D180 BDFM

\begin{tabular}{ccccc}
\hline & & One loop & Two loops & Three loops \\
\hline \multirow{2}{*}{ CCM } & $R^{\prime}{ }_{r}(\Omega)$ & 3.47 & 1.87 & 1.54 \\
& $L^{\prime}{ }_{r}(m H)$ & 117.7 & 64.1 & 52.4 \\
\hline \multirow{2}{*}{ WFM } & $R^{\prime}{ }_{r}(\Omega)$ & 3.59 & 1.94 & 1.60 \\
& $L^{\prime}{ }_{r}(m H)$ & 121.8 & 67.6 & 54.1 \\
\hline
\end{tabular}

TABLE IV

PARAMETER CALCULATION OF 42-SLOT BAR CAGE ROTOR WITH DIFFERENT NUMBER OF LOOPS FOR D180 BDFM

\begin{tabular}{ccccc}
\hline & & One loop & Two loops & Three loops \\
\hline \multirow{2}{*}{ CCM } & $R^{\prime}{ }_{r}(\Omega)$ & 3.19 & 1.52 & 1.23 \\
& $L^{\prime}{ }_{r}(m H)$ & 108.4 & 55.3 & 43.3 \\
\hline \multirow{2}{*}{ WFM } & $R^{\prime}{ }_{r}(\Omega)$ & 3.12 & 1.60 & 1.27 \\
& $L^{\prime}{ }_{r}(m H)$ & 110.7 & 58 & 45.1 \\
\hline
\end{tabular}

The optimised loops spans for the three-loop designs are given in Table $\mathrm{V}$.

TABLE V

OPTIMIZED LOOP SPANS FOR MINIMUM ROTOR PARAMETERS

\begin{tabular}{lccc}
\hline \multirow{2}{*}{ Rotor type } & \multicolumn{3}{c}{ Loop span (degree) } \\
\cline { 2 - 4 } & Inner loop & Middle loop & Outer loop \\
\hline Nested-loop & $27^{\circ}$ & $42^{\circ}$ & $54^{\circ}$ \\
Bar cage & $24^{\circ}$ & $38^{\circ}$ & $50^{\circ}$ \\
\hline
\end{tabular}

\section{B. Saturation Effects}

The optimized loop spans obtained for minimum BDFM rotor parameters generally result in unequal rotor teeth widths as shown in Fig. 6. This may cause iron saturation and hence excessive rotor core losses in the narrower rotor teeth. Therefore, special care must be taken in determining optimized loop spans and width of 
rotor teeth in order to avoid saturation.

An approximation for the magnetic loading of the BDFM was given in [15] as:

$$
\bar{B}=\frac{2 \sqrt{2}}{\pi} \sqrt{B_{1}^{2}+B_{2}^{2}}
$$

The maximum flux densities in the teeth, $\hat{B}_{t}$, must be chosen according to some criterion e.g. to avoid saturation in the iron or to minimize core losses. It was shown in [16] that the minimum teeth width, $w_{t}$ for both the rotor and stator laminations to avoid saturation at rated operating conditions of the machine can be calculated using the following equation:

$$
w_{t}=\frac{\sqrt{2} \pi d}{n_{s} \hat{B}_{t}}\left(B_{1}+B_{2}\right)
$$

where $d$ is the air gap diameter, $n_{s}$ is the number of rotor or stator teeth and $B_{1}$ and $B_{2}$ are rms values of air gap magnetic field density generated by PW and CW. From (7), the minimum required rotor tooth width, $w_{t}^{r e q}$, for 36slot and 42-slot rotors with the air gap diameter of 165 $\mathrm{mm}$ and magnetic loading of $0.52 \mathrm{~T}$ can be determined as $8.8 \mathrm{~mm}$ and $7.5 \mathrm{~mm}$, respectively.

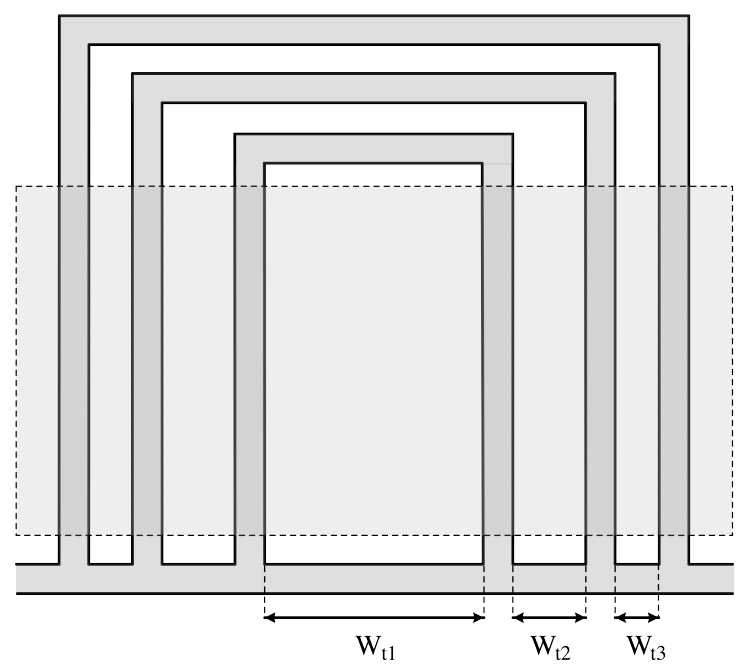

Fig. 6: Uneven distributions of rotor slots as a result of loop span optimization.

Table VI shows the widths of the teeth as labelled $w_{t l}$, $w_{t 2}$, and $w_{t 3}$ in Fig. 6 . As can be seen from Table VI, the widths of teeth $t_{2}$ and $t_{3}$ are considerably lower than the minimum required width to avoid saturation. In addition, the negative value for $w_{t 3}$ in the case of bar cage rotor implies that the design of a bar cage rotor with three internal loops and optimized loop spans is not physically practical and therefore a design with fewer number of loops should be considered.

TABLE VI

ROTOR TEETH WIDTHS FOR THE OPTIMISED ROTOR DESIGNS

\begin{tabular}{lcccc}
\hline \multirow{2}{*}{ Rotor type } & \multicolumn{4}{c}{ Tooth width (mm) } \\
\cline { 2 - 5 } & $\boldsymbol{W}_{\boldsymbol{t}}^{\boldsymbol{r e q}}$ & $\boldsymbol{W}_{\boldsymbol{t} \boldsymbol{1}}$ & $\boldsymbol{W}_{\boldsymbol{t} \boldsymbol{2}}$ & $\boldsymbol{W}_{\boldsymbol{t} \mathbf{3}}$ \\
\hline Nested-loop & $8.8 \mathrm{~mm}$ & $25 \mathrm{~mm}$ & $4.3 \mathrm{~mm}$ & $0.5 \mathrm{~mm}$ \\
Bar cage & $7.5 \mathrm{~mm}$ & $21.8 \mathrm{~mm}$ & $7.1 \mathrm{~mm}$ & $-1.1 \mathrm{~mm}$ \\
\hline
\end{tabular}

\section{Optimized Prototype Rotors}

Two prototype rotors, a nested-loop and a bar cage structure are designed for optimizing the rotor equivalent circuit parameters while keeping the iron saturation at its acceptable limit. The design details are shown in Table VII. The nested-loop rotor has 36 slots and three loops per nest. The rotor teeth have equal widths close to the required value of $W_{t}^{r e q}$, obtained from (6). The bar cage rotor has 30 slots and two internal loops. The teeth are designed to have equal widths to meet saturation requirements.

TABLE VII

\begin{tabular}{|c|c|c|c|}
\hline \multicolumn{2}{|c|}{ Rotor type } & Nested loop & Bar cage \\
\hline \multicolumn{2}{|c|}{ No of slots } & 36 & 30 \\
\hline \multirow{3}{*}{ Span } & Loop 1 & $10^{\circ}$ & $12^{\circ}$ \\
\hline & Loop 2 & $30^{\circ}$ & $36^{\circ}$ \\
\hline & Loop 3 & $50^{\circ}$ & - \\
\hline \multicolumn{2}{|c|}{ Tooth width } & $8.6 \mathrm{~mm}$ & $10.6 \mathrm{~mm}$ \\
\hline \multicolumn{2}{|c|}{$W_{t}^{r e q}$ from (6) } & $8.8 \mathrm{~mm}$ & $10.5 \mathrm{~mm}$ \\
\hline
\end{tabular}

SPECIFICATIONS OF THE NEW DESIGN ROTORS FOR D180 BDFM

The BDFMs with new rotor designs are modelled using Finite Element Analysis (FEA). Fig. 7 shows the meshes developed for the two rotors. Non-linear models were used to assess the magnetic circuits and saturations levels of the machine at synchronous mode and rated conditions. It was observed that the flux densities in different locations of the rotor teeth and rotor back iron regions are close to the target values set out at the design stage. However, for the nested-loop rotor, where the rotor teeth widths are thinner than the minimum required value, a degree of saturation was observed specially in the roots of the teeth at rated PW and CW voltages.

The linear FEA model is used to derive the rotors equivalent circuit parameters. The parameters have also been obtained using analytical CCM and WFM. The parameters are shown in Table VIII.

\section{DISCUSSION AND CONCLUSIONS}

From Table VIII, it is evident that the parameters values obtained for the optimized rotors are significantly lower than those of previous rotors for D180 BDFM shown in Table II. The values of $n_{r}$ for both optimized rotors are close to the optimum value of 0.707 .

TABLE VIII

ROTOR EQUIVALENT CIRCUIT PARAMETERS FOR D180 BDFM NEWLY DESIGNED ROTORS

\begin{tabular}{lcccc}
\hline & & $\boldsymbol{R}_{\boldsymbol{r}}(\boldsymbol{\Omega})$ & $\boldsymbol{L}_{\boldsymbol{r}}(\boldsymbol{m H})$ & $\boldsymbol{n}_{\boldsymbol{r}}$ \\
\hline \multirow{3}{*}{$\begin{array}{l}\text { Nested Loop } \\
\text { Rotor }\end{array}$} & CCM & 1.45 & 47.5 & 0.735 \\
& WFM & 1.49 & 50.7 & 0.733 \\
& FEA & 1.51 & 52.1 & 0.730 \\
\hline \multirow{3}{*}{ Bar Cage } & CCM & 1.37 & 48.6 & 0.716 \\
Rotor & WFM & 1.39 & 53.5 & 0.713 \\
& FEA & 1.43 & 51.3 & 0.717 \\
\hline
\end{tabular}


There are four major sources of leakage permeance considered in the analysis: slot, tooth-top, overhang and zigzag permeances. Among the leakage terms, the slot leakage in most cases has the largest contribution in the winding leakage [16]. The slot leakage permeance is inversely proportional with the slot pitch and the slot width. Therefore, for the 30-slot bar cage rotor with larger slot pitch and slot width than a 36-slot nested-loop rotor, lower $L{ }_{r}{ }_{r}$ is expected. Nevertheless, it should be noted that higher number of loops in the nested-loop rotor has a positive effect on $L^{\prime}{ }_{r}$ reduction by creating smoother EMF. The $L^{\prime}{ }_{r}$ values, estimated from different methods and shown in Table VIII, show that the difference between the two rotor designs is not significant.

However, there is, in average, a $6.5 \%$ reduction in the referred rotor resistance of the bar cage rotor as compared to that of the nested-loop rotor. This is mainly due to the increase in the rotor bars cross section as a result of lower number of required slots. The advantage of lower rotor resistance as well as better rotor performance in terms of iron saturation makes the bar cage design a better rotor choice for large-scale BDFMs.

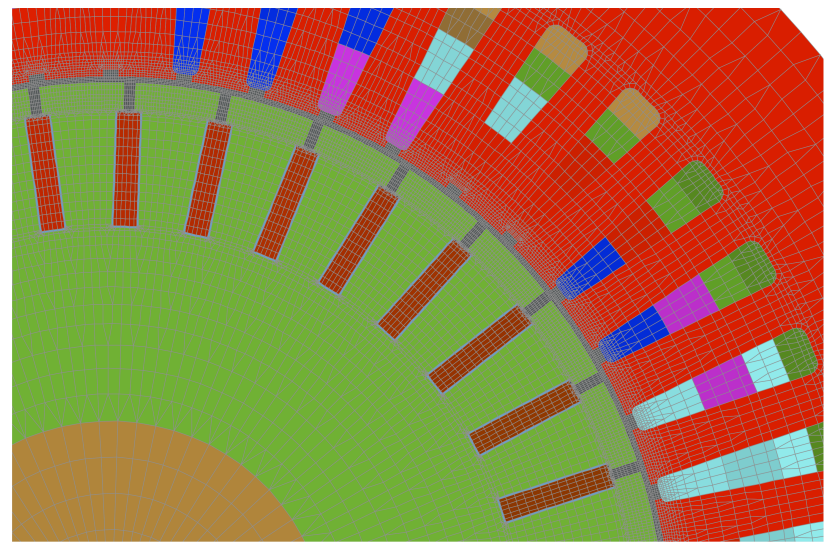

(a) 36-slot nested-loop rotor

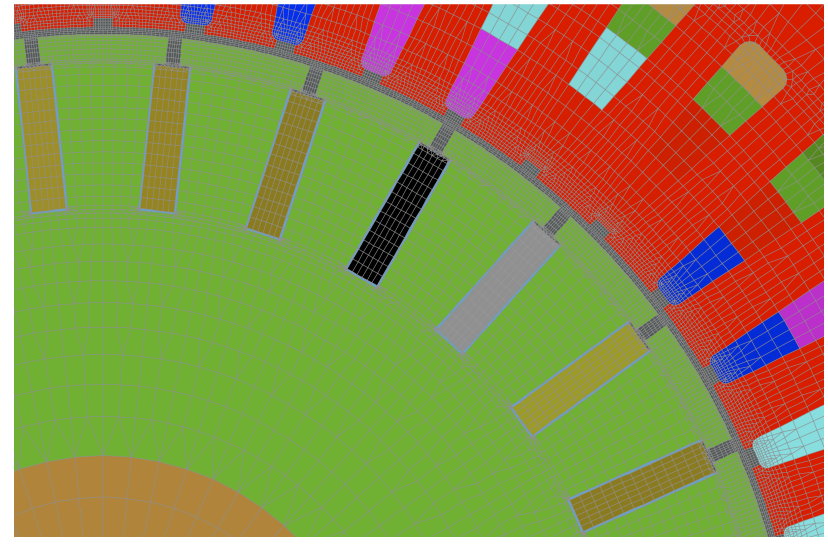

(b) 30-slot bar cage rotor

Fig. 7: FE modeling of D180 BDFM with new optimized rotors

\section{REFERENCES}

[1] McMahon, R., Wang, X., Abdi, E., Tavner, P., Roberts, P. and Jagiela, M.: 'The BDFM as a Generator in Wind Turbines', Power Electronics and Motion Control Conference, 2006.
[2] Carlson, R. Voltolini, H. Runcos, F. Kuo-Peng, P. Baristela, 'Performance analysis with power factor compensation of a $75 \mathrm{~kW}$ brushless doubly fed induction generator prototype'. IEEE Int. Conf. Electric Machines \& Drives, Antalya, Turkey, May 2007, vol. 2, pp. 15021507.

[3] Liu, H., Xu, L.: ' Design and performance analysis of a doubly excited brushless machine for wind power generator application' . IEEE Int. Symp. Power Electronics for Distributed Generation Systems, Hefei, China, June 2010, pp. $597-601$.

[4] E. Abdi, R. McMahon, P. Malliband, S. Shao, M. Mathekga, P. Tavner, S. Abdi, A. Oraee, T. Long, and M. Tatlow, "Performance analysis and testing of a $250 \mathrm{kw}$ medium-speed brushless doubly fed induction generator," Renewable Power Generation, IET, vol. 7, no. 6, pp. 631 638, 2013.

[5] Broadway, A.R.W., Burbridge, L.: 'Self-cascaded machine: a low speed motor or high frequency brushless alternator', IEE Proceedings, volume 117, pp. 1277-1290, 1970.

[6] P. Tavner, R. McMahon, P. Roberts, E. Abdi, X. Wang, M. Jagiela, and T. Chick, 'Rotor design and performance for a BDFM'. International Conference on Electrical Machines (ICEM), Sept 2006.

[7] T.G. Logan, R.A. McMahon, P.J. Tavnver, S. Tohidi, 'A Comparison of Cage and i-Loop BDFM Rotors', 6th IET Int. Conf. on Power Electronics, Machines and Drives (PEMD), 2012.

[8] Gorginpour, H.; Jandaghi, B.; Oraee, H.; 'A Novel Rotor Configuration For brushless Doubly-Fed Induction Generators', IET Electric Power Applications, Volume 8, Issue 2, Feb 2013.

[9] R. McMahon, P. Tavner, E. Abdi, P. Malliband, and D. Barker, "Characterising brushless doubly fed machine rotors," Electric Power Applications, IET, vol. 7, no. 7, pp. 535-543, Aug 2013.

[10] P. C. Roberts, R. A. McMahon, P. J. Tavner, J. M. Maciejowski, and T. J. Flack, "Equivalent circuit for the brushless doubly fed machine (BDFM) including parameter estimation and experimental verification," IEE Proc.Electr. Power Appl. vol. 152, no. 4, pp. 933-942, Jul. 2005.

[11] A. Oraee, E. Abdi, R. McMahon, "Converter Rating Optimization for Brushless DFIG Steady-state and Transient Operations", Renewable Power Generation, IET, 2014.

[12] A. Oraee, E. Abdi, S. Abdi, R. McMahon, "Effect of rotor winding structure on the BDFM equivalent circuit parameters", IEEE Transactions on Energy Conversion, Vol. 30, No. 4, Dec 2015.

[13] R. McMahon, P. Malliband, M. Tatlow, E. Abdi, A. Broekhof, S. Abdi, "Rotor parameter determination for the brushless doubly fed induction machines", IET Electric Power Applications, Vol. 9, Iss. 8, pp. 549-555, 2015.

[14] S. Abdi, E. Abdi, A. Oraee, R. McMahon, "Equivalent circuit parameters for large brushless doubly fed machines", IEEE Transactions on Energy Conversion, Vol. 29, NO, 3, Sep 2014.

[15] X. Wang, R. A. McMahon, and P. J. Tavner, "Design of the brushless doubly-fed (induction) machine," in Proc. IEEE Int. Conf. Elect. Mach. Drive, May 2007, pp. 1508-1513.

[16] S. Abdi, E. Abdi, A. Oraee, R. McMahon, "Optimization of magnetic circuit for brushless doubly fed machines", IEEE Transactions on Energy Conversion, Vol. 30, No. 4, December 2015. 